\title{
Singing is a Celebration of Language: Using Music to Enhance Young Children's Vocabularies
}

\author{
KARI-LYNN WINTERS, SHELLEY M. GRIFFIN \\ Brock University
}

\begin{abstract}
Music engages children in language learning, offering them opportunities to understand and express their ideas and communicate with others in ways that go beyond words. This article, based on two ethnographically-framed studies and the use of two real-life vignettes, demonstrates how singing and musical experiences (e.g., composition, soundscapes, musical improvisation) have the power to enhance children's lexical acquisition and semantic knowledge at various levels of development. Results demonstrate that singing and musical experiences, whether biologically or socially shaped, provide opportunities to celebrate language and enhance young children's vocabulary building.
\end{abstract}

During a library session for parents and tots, a six-month old seems to imitate the words and facial expressions of her singing mother's face. At home, a two-year old with limited vocabulary sings an eleven-word-phrase, "...we are going to moon, five, fwee, two, one, bwast off!" In a Grade 2 classroom, one student, while musically engaging with a picturebook, learns the meaning of the word frumpy; meanwhile another coins the word opadescent (a combination of "opalescent" and "iridescent") after composing soundscapes that accompanied the stories, The Camel Dances (Lobel, 1980) and Grandfather Twilight (Berger, 1984). In a gymnasium in front of the whole school, a teen overcomes his challenges with stuttering by listening to music while delivering a motivational speech. What do these situations have in common? They are all examples of language celebrations, each made possible through singing and musical experiences.

Young children have a natural propensity to move, clap, dance, and sing out loud when a rhythm or melody appeals to them (Campbell, 2010). Yet, beyond intrinsic motivation, art forms such as music engage children in language learning, offering them opportunities to understand and express their ideas and communicate with others. Furthermore, singing and music have the power to promote and enhance children's lexical acquisition and semantic knowledge at various levels of development.

In this article, we (the authors) explore the powerful, every day practices that children embody in their daily music making. Specifically, we examine how children use music to develop their vocabularies (both lexical acquisition and semantic knowledge together). Lexical acquisition is defined as the total words that an individual can remember and say proficiently. Its complement, semantic knowledge, refers to the meanings of these words and the child's ability to use these words appropriately in 
phrases and sentences (Stone, Silliman, Ehren, \& Apel, 2004). Words and word meanings, can you have one of these without the other? When we explore lexical acquisition and semantic knowledge together, we strengthen and broaden a child's complete vocabulary.

Additionally, our article explores the intricacies of biological linguistic structures and the influences of sociocultural contexts and practices. Through two selected vignettes from children's everyday experiences, we illuminate the ways singing and musical experiences promote communication and vocabulary development. Our guiding research questions include: (a) How is vocabulary (whether gained through music or language) biologically and socioculturally shaped within situated contexts? (b) What parallels and distinctions exist between music-based or language-based vocabulary acquisitions? (c) What everyday life experiences demonstrate children's developing lexical acquisition and semantic knowledge?

\section{Theoretical Perspectives on Music and \\ Language Vocabularies: Innate and Learned}

Music and language are meaningful because they define identities, represent thoughts, symbolize feelings, mobilize knowledge, and unite communities through social practices. There has been some debate among researchers as to whether music and language are determined. In the 1970s, Streeter (1976) found that infants' first utterances were similar, despite being on different continents. She proposed that children might have innate mechanisms to perceive language structures and sound patterns. Nearly 10 years later Chomsky, predominate linguistic researcher (cited in Baby Talk, PBS, 1985), asserted that humans have the inherent capacity to communicate. He proposed that all humans have a language acquisition device that controls a child's interpretation and production of speech. His research demonstrated that when children learn to speak, they frequently demonstrate similar language patterning, despite different sociocultural contexts. Later, Locke (1990) discovered that babies have innate abilities to discriminate between language and other vocal sounds, including musical ones.

Furthermore, some researchers believe that music and language are innate and are inseparably interlinked as codependent systems in the brain (Fedorenko, Patel, Casasanto, Winawer, \& Gibson, 2009; Peretz, 2006). Lise Eliot (2000), a neurobiologist and author of What's Going On In There, stated that the human brain is innately biased for language and music as forms of communication. She explained that verbal language and singing both help to form localized and distinct sections in the brain.

On the other hand, children engage daily in a variety of linguistic and musical experiences (Campbell \& Wiggins, 2013; Griffin, 2007; Smithrim \& Upitis, 2007). Graham (2000) noted that children live in a world of music - such sounds lull children to sleep, provide background for activities, accompany play, and are integrated in television, video games, and computer programs. These experiences shape their thinking and their language development. As Campbell (2004) articulated, "Music [and language do] not exist in a vacuum" (p. 217). Children are enculturated into musical experiences as music encircles them in their daily worlds. Music is not separated from children's culture; it 
interplays and intersects with their lived understandings of language. The various contexts in which children experience music provide understandings of their sociocultural-linguistic worlds.

Over the past several decades, researchers (Berko-Gleason, 2001; Kit, 2003; Manolson, 1992; Montgomery, 2012a) have suggested that when children are exposed to words - whether through musical or verbal language - they build their capacities to understand and express language more efficiently than those who have less exposure. Additionally, children who have had language modeled for them will also be more likely to have larger vocabularies than those who do not receive the same degree of modeling. Exposing children to rich verbal surroundings allows them to hear and participate in the sonic worlds around them. Singing can also benefit a child's language development, perhaps because of the similarities between musical and verbal language (Cohen, 2010; Montgomery, 2002; Piro \& Ortiz, 2009). This suggests that music vocabularies and language might be heavily dependent on exposure and social contexts. Campbell (2004) indicated that, "Our surroundings are as musical as they are visual, and the unavoidable sonic textures blanket us in our every circumstance" (p. 2). She further acknowledged that the sociocultural context of a child accounts for the willingness to engage with musical experiences and language.

Although debated, other researchers (North \& Hargreaves, 2008) supported that vocabulary acquisition is influenced by both a biological and sociocultural basis of development. For example, Tomasello (2003) argued children have powerful brains that predispose them to new vocabularies. However, they are also motivated by, and may make more gains cognitively and linguistically, when in conversations with others. Together, an individual's innate propensity towards music and language, as well as his or her sociocultural experiences, family beliefs, and musical values play a role in a child's musical and linguistic development (Campbell, 2004).

\section{Parallels and Distinctions between Music and Language}

Music education researchers have offered compelling comparisons between music and language (Bernstein, 1976; Lehrdahl \& Jackendoff, 1983; Montgomery, 2002, 2012a, 2012b). According to Montgomery (2002), music and language parallel each other in terms of grammatical structures, phonemes (the smallest sound units in language), syntax (rules governing the combination of phonemes into sound sequences), and semantics (ways in which meaning is assigned to or carried by these sound sequences). In Montgomery's (2012a) more recent research regarding song-based picture books and their connections to children's early literacy development, she advocated that songs and song-based picture books support children's engagement with the sounds of language and their continued growth in vocabulary. In the next sections, we highlight some parallels and distinctions between music and language.

\section{Communicative Potentials}

Music and language are both communicative forms. They consist of systems by which we can interpret and produce thoughts, images, and feelings. Music that includes 
lyrics provides a framework for children to hear and understand new lexical items and comprehend concepts (Montgomery, 2012a). Lyrics also help young artists express their emotions and communicate the depth of their musical experiences through song. Perhaps this is because lyrics help children focus on the sounds of language and phonological awareness (Montgomery, 2012b). Each has the potential for people to make connections and to impart a common understanding among a culture of people.

\section{Structures and Elements}

Music and language both follow a linear structure until a phrase or sentence is completed. Moreover, music with words embedded within it and conversational language share elements of musicality such as timbre (tone colour), pitch (highness or lowness of a sound), dynamics (volume), beat (underlying pulse), rhythm (varied durations of notes or silences over a steady beat), tempo (speed of the beat), and metre (emphasis of certain beats over others) (Montgomery, 2002). Each system of communication may also encourage skills such as inflection, turn-taking, timing, listening, concentrating, and an awareness of words. However, each system is highly structured in unique ways as well; within situated contexts, each system of communication carries its own affordances or semiotic potential (Winters, 2010). Despite the parallels described here, well-known music education philosopher, Reimer (2003) contrasted the processes of music and language. He wrote:

In language, meanings are created and shared through the process of communication. In music, meanings are created and shared through the processes of artistic musical creation and aesthetic musical responsiveness. . . . Nothing about the process just described applies to the processes of musical creation and response. (pp. 136-137)

We interpret this difference as articulating precise meaning through language versus evoking emotional content. Reimer (2003) used the following example: in language, a person may say, "Please close the door." Whereas in music with lyrics, the artist may sing, "No one ever cares about privacy around here." In the latter example, the listener still comprehends the message, but cannot help but feel empathy toward the singer conveying the message. Here, an inference is made, drawing in the listener. In both examples, though the content may be similar, the intent is distinct. Further to this, Reimer (2003) suggested that, "Musical creation is a process of exploration and discovery" ( $p$. 137). Music is not just about encoding and decoding messages, but rather, it is about the "feelingful qualities of sound" (p. 137). Music has the capacity to go beyond words as the sonic interplays with the lexical. It is layered and has the capacity to have aesthetic nuances in this way.

Alternatively, language is characterized as a process of encoding/decoding information, as well as expressing/receiving messages. Hence, perhaps this is why language is called expressive and receptive communication. The following two examples illustrate this idea. First, in the stages of infant pre-verbal communication (Hoff \& 
Naigles, 2002), babies use crying and cooing as direct ways to communicate their feelings of hunger, anger, discomfort, and loneliness, as well as happiness. These sounds are not communicated for the purposes of an aesthetic experience. Rather, the child is attempting to transmit a message with as little interference as possible (Reimer, 2003). A second example demonstrating the directness of language is rooted in cognitive processing theory (Hoff \& Naigles, 2002). Here, infants learn to complete a word so that it communicates direct information. For example, when a children's author introduces him/herself to a group of children and says, "Hi, I am an au-...", children use contextual cues to anticipate the final syllable as "-thor" making the word, "author" as opposed to "-strich" making the word, "ostrich". In other words, when children are using language, they are making direct links to receive and express information. As language development researchers have suggested, infants' brains are constantly figuring out which sounds will follow each other so that the lexical item or the sentence makes sense (Levine \& Munsch, 2010).

\section{Authentic and Imagined Opportunities}

Another parallel between language and music is that, like books, songs broaden children's vocabularies because they provide authentic opportunities for making sense of the world in and outside of a range of imagined and real contexts (Montgomery, 2012a). Barrett (2006) also argued that songs provide the platform for inventing creative thought - something poets and authors also do. This ability is extremely valuable in later years when the child becomes literate and begins writing narratives or informational texts. Songs that include lyrics lay the foundation for future language growth: phonological awareness, vocabulary development, and text comprehension (Montgomery, 2012b).

\section{Gestures and Embodiment}

Language play and childhood songs help toddlers acquire and memorize words as it encourages them to actively embody and imitate the celebration of rich language. Don Campbell (2000), author of The Mozart Effect, believed that human communication begins not in speech but in the body. Music with fingerplays and rhymes encourages children's physical engagement and then call attention to the words. Movement is an indispensible part of learning language, for it helps children develop word meanings and deeper comprehension (Winters, 2013). When a child claps or hits a drum to the rhythm of the lyrics or poem he/she begins to grasp a basic knowledge of segmentation (knowing where words begin and end), which proves to be very helpful in the vocabulary building process. Futhermore, most literacy specialists would agree that the child who has the preliterate ability to discriminate between and segment words or distinguish rhymes (word families) is destined to have an easier time writing and reading printed text (Montgomery, 2012a).

\section{Research Design}

The literature review provided above begins to demonstrate some of the ways music and language are biologically and socioculturally shaped, as well the parallels and distinctions between music and language. In the following section, we draw attention to 
our research design. We offer two real-life situations as vignettes, alongside a discussion, to show some concrete instances where vocabulary was developed, extended, and celebrated.

The vignettes that follow come from two ethnographically-framed studies (Bresler, 2006; Creswell, 2012; Griffin, 2009, 2011; Van Maanen, 1988) that took place in a west coast urban community in Canada. During these studies, the first author visited several community centres, play groups, libraries, home environments, and schools, looking for evidence of language development and the integration of art forms such as music, drama, visual arts, and media. The studies ranged from one to two years. Although a range of art forms were researched, this article focuses specifically on singing and musical experiences. In each study, the first author was invited into communities, where she observed, participated in, and periodically was invited to teach lessons. Data sources included fieldnotes, interviews, and some voice recordings.

The ethnographic framework was chosen because it allowed for developing understanding of participants' lives in a natural setting over time with a person or group of people (Emerson, Fretz, \& Shaw, 2011; Van Maanen, 2011). The studies were facilitated by participating in:

... people's daily lives for an extended period of time, watching what happens, listening to what is said, and/or asking questions through informal and formal interviews, collecting documents, and artefacts - in fact, collecting whatever data are available to throw light on the issues that are the emerging focus of inquiry. (Hammersley \& Atkinson, 2007, p. 3)

Formulating meaning and building this understanding over time was essential in order to comprehend how children use music to enhance their vocabularies.

\section{Vignettes and Discussions}

Vignette One: A Two-Year Old Recontextualizes

The two-year old boy, Ian (pseudonym), mentioned at the onset of this article was a member of a playgroup that took place weekly (1 hour in the morning) in an urban West Coast community centre in Canada. At this playgroup, young children had the opportunity to play with one another, to explore new equipment (e.g., climbing structures, slides, mats) and toys (e.g., ride on toys, tricycles, balls). Parents were expected to be actively watching their children and be within close proximity. This type of free-play took up the majority of the time (approximately 40 minutes). Then, after a collaborative clean-up, there was an opportunity to participate in a "parent-information session/song circle" led by an early childhood educator. Other support staff who were frequently present included a speech therapist, an occupational therapist, and a community health nurse. Using the remaining minutes of the playgroup, this team would offer information about relevant topics for the adults (e.g., immunizations, child development, and access to resources) interspersed with finger plays and songs for the children. To alert the children that the playgroup was ending for the day, the leaders would sing a song called Zoom. 
During the study, the researcher witnessed Ian physically engaging in song through body percussion and movement, though he could not yet articulate the words in the song. Week after week, he would show his excitement for the Zoom song by pretending to be the rocket, tapping his leg, clapping, and so forth. Early on in the study, this young boy barely spoke at playgroup. To the researcher he seemed engaged - an industrious and active child - but uninterested in speaking. The phrases that were recorded (Fieldnotes, March, 2002) of his speaking at the playgroup included:

1. "I hungee"

2. "I is pwaying"

3. "No, mommy. Mine!"

4. "Stop! Det out!"

5. "Daddy, pick EE-um up."

Much of the language Ian did use was expressive commands, often in the present tense.

The community speech therapist who worked at the playgroup also noticed that Ian was late in developing his vocabulary motor skills. She recommended that he be a study participant because of his challenges with enlarged adenoids, which pushed his tongue forward, making speech difficult. In conversation with the young boy's mother, she indicated that her child was born premature. She felt that Ian was continually behind in language (e.g., forming consonant sounds and digraph sounds) and physical development (e.g., crawling, walking). Ian began speech therapy shortly after; he was 26 months old. The half-hour speech therapy sessions occurred in the morning on a different day than the playgroup. This service could be accessed free of charge.

At his speech therapy sessions, the speech therapist played with Ian, while encouraging him to talk. For example, she would set out a play barn with animals before he would enter the room. Then during the half hour, she would encourage him to name the animals and tell her what was happening in the play. She also asked him many questions. Sometimes he would answer, at other times he would not (Fieldnotes, May, 2002). She spoke to Ian's parents after every session suggesting that they practice certain phrases and sounds (e.g., the "l" phoneme, "th" diagraph, past tense words) (Fieldnotes, June, 2002). "You are your child's best teachers" (Fieldnotes, July, 2002). She also suggested making talking fun and playful through songs and rhymes.

After five more months of community playgroup and speech therapy-according to the speech therapist - he was making progress. He could now articulate longer phrases, vary his sentences, and he was beginning to use the past tense (Fieldnotes, August, 2002).

1. "No! I not stop, Mommy."

2. "No, mommy. Give back. Mine!"

3. "Daddy picked me up. "

4. "I went in car last night."

5. "Who loves EE-um?"

6. "Where Chipper (a stuffed toy) go?" 
Later that month, following a playgroup one morning, while in the kitchen with his mother, Ian sang, “...we are going to moon, five, fwee, two, one, bwast off!", while pretending to transport himself out of his real kitchen context and into the imagined land of rocket ships. He used a rocket ship and blasted off. The articulation of this Zoom song, learned in a community playgroup, was a surprise to his mother. At this point, she had only witnessed him putting together short phrases.

\section{Vignette One: Discussion}

Here, Ian demonstrates his ability to recontexutalize language through his knowledge of songs and finger plays. One does not have to look far to see how effective song is for lexical acquisition. One of the best and closest examples of this is when a child learns the 26 new lexical items that comprise our Alphabet song. Imagine memorizing these new symbols without the song. Here, music is tremendously helpful for acquiring lexical items and moving towards a successful path of literacy.

The way song heightens lexical and semantic knowledge can perhaps best be described as a spiral progression (cf. Montgomery, 2002, in her description of experiencing music in a spiral progression). Often, the child is first taught a song through the process of rote. After several repetitions of the song, the child encodes the words into memory. Meanings are attached to these words and built upon, increasing the child's vocabulary. Therefore, the spiral continues upward with children learning even more complex songs and broadening their vocabulary.

The Zoom song discussed in the vignette above provides fertile ground for generative and imagined language performance and creative elaboration. The speech therapist with which the first author spoke mentioned that true lexical acquisition begins early, traditionally with the first word, usually occurring between the ages of 12 and 18 months of age. At this stage of development, toddlers begin to imitate speech sounds, quickly acquiring and consolidating more and more words. Many of these transitional words include the actual sounds of the word referents. For example, a dog becomes a woof and a clock becomes a tih, tih. It is also at this stage of development that we as adults begin to witness a child's development of semantics. When asked whether speech was biologically or socially shaped, the speech therapist responded that she felt it was "both together". She used a model of a child and a developmental chart to demonstrate some of the most difficult word patterns and this child's particular challenges. She also shared how some of her clients have no physical or biological challenges but struggle with language due to lack of exposure or motivation.

According to the speech therapist, Ian was "a little behind other children his age in his expressive language development, perhaps because of the position of his tongue". At the same time, as the study progressed, the speech therapist confirmed that this child's "receptive language skills were developmentally at par with other children his age" (Fieldnotes, March, 2002). It was clear that this toddler was beginning to understand that there was an arbitrary relationship between the word and its accompanying sign (Pan, 
2001). For example, he did not call a dog a woof. He called it a $d o g$, which is arbitrary for a child learning language.

The therapist's advice to the parents was to expose him to as much language as possible. She suggested that gestures and signs might also accelerate his expressive skills (e.g., fingerplays, toys and dolls, or sign language). When children are given the opportunity to understand a song kinesthetically, it gives them the means to understand more fully what they have experienced-hence, enhancing their vocabularies. Fingerplays and singsong nursery rhymes with their gestures and repetitive melodies engaged this toddler physically, helping him to more efficiently encode and communicate his past experiences in playgroup. Acredolo and Goodwyn (1996), authors of Baby Signs, suggested that singing, when combined with understandable movements (e.g., finger plays) that represent words and concepts not only reduces frustration, but also enables toddlers to become more effective communicators. Here, this child used language and gestures together, making remarkably fast transitions from his double word combinations to longer word phrases.

\section{Vignette Two: Coining a New Word}

In another study with school-aged students, Winters (2013) found that using music with picturebooks is a wonderful way to improve comprehension. Situated in an inner-city context, the recommended Grade 2 classroom was suggested by a librarian as a possible site for data collection. The majority of students in this classroom were from First Nations and Asian heritages. Some of the students had been diagnosed with Fetal Alcohol Syndrome (FAS) and came from impoverished home environments. The researcher came into the classroom bi-weekly over a period of one year. During a science class, the teacher was utilizing soundcapes and songs with the picture book, Grandfather Twilight (Berger, 1984) to teach the students about light and luminosity. Several words about brightness, colour, and reflection were introduced, including opalescent and iridescent. In groups, children were asked to look up words in the dictionary to find their meanings. Following this, they were invited to compose a soundscape or song using the new words. Using the melody of Twinkle Twinkle Little Star, one child coined the word opadescent (a combination of opalescent and iridescent) in her group composition. Below is an excerpt from the transcribed conversation that followed.

Student One (singing): ... because the light is bent...

Student Two (singing): Like a prism...Opadescent.

Student One: Which word are you using here? Opalescent or iridescent?

Student Two: Both! It means all the colours like pink and blue and white from different angles... [The student appears to be combining opalescent and iridescent!]

Student One: That's true. Yeah!

Student Two: It's like... that's like you put the... the... what's it called again? Crys...

Student One: An opal? 
Student Two: No. Cryss...

Student Three: A pearl?

Student Two: A crystal. Like a prism.

Student Three: Ohh. Yes. That works.

Later, when the teacher asked the meaning of the new word, the students clearly articulated the meanings of both opalescent and iridescent. Thus, the song and the language utilized to compose the song served as a platform for the children to remember the pronunciation and describe the meanings of new vocabulary.

\section{Vignette Two: Discussion}

Music continues to influence lexical and semantic development into the primary school years (Harp, 1988). For school-aged children, lexical acquisition and semantics become more and more playful as children learn that words can have several meanings. This is the stage of development where jokes, riddles, and made-up songs can greatly amuse a child. Symbolic language, metaphor, and irony also begin to play a larger role in communication. Here the children are working together, scaffolded by their prior instruction in creating definitions, to come up with their own song lyrics. They were able to move language from the real context (in the present with gestures, turn-taking) into the imagined context (inside the song; inside the story), which is characteristic of their developmental literacy levels. In other words, the child has the potential to understand and use the acquired language, and even embed it in an imagined context - a "Secondary World"- often through the use of songs or soundscapes (Benton, 1992).

Interviewing the teacher afterwards, she mentioned that the children used "a more interesting and accurate vocabulary" to describe the meaning of the book and their pictures after experiencing music and story together. "Words like wise, prism, and twilight were used, replacing words like old, rainbow, and night-time... One student made up a new word, a combination of opalescent and iridescent to describe the trail that Grandfather Twilight left behind."

The school-aged children in this project demonstrated in this vignette how their vocabulary was growing as they progressively integrated their word knowledge and comprehension. Students asked others to explain a word if they did not understand the lyrics. Once defined within the situated context (e.g., the picturebook), the children felt less inhibited to use the recently learned words or even coin new ones.

For most students in the study, songs and soundscapes (when used as tools) gave them more ways to understand and express themselves, giving them the potentials for new connections or experiences. Using music even in the background as soundscapes also evoked new emotions, which proved to be very powerful. The student's vocabulary was enhanced since they had the opportunity to "transact"-feel the words by seeing and living through the story kinesthetically (Rosenblatt, 1978).

Giles, Andre, Dye, and Pfannesstiel (1998) have done further research in this area. For example, children studied songs of the time and learned how slaves used code songs to communicate, especially when they were making their plans to escape. The children in 
their study could better relate to the predicament of the slaves. The music had the power to increase the students' range of language opportunities, allowing them more elaborate connections with the literature and the historical context (Giles et. al., 1998). Here, the collaborative use of music and language validates the vocabulary-building experience.

\section{Conclusion}

In both vignettes, the musical engagement propelled the students to embody the connections and feelings they previously had not articulated, demonstrating vocabulary growth. The vignettes demonstrated that when singing and musical experiences were used in homes, classrooms, libraries, parent groups, and other situated contexts within the study, the words left lasting impressions with the children. For instance, several weeks after their artistic responses to the story, the Grade 2 children in the study could still remember the feelings they had experienced and still recalled the lexical items (e.g., opalescent and iridescent), as well as their associated meanings.

Throughout this article, we have tried to demonstrate parallels and distinctions between music and language, stressing that when children use singing and musical experiences as an integral means of acquiring and consolidating language, they show increased engagement and have the potential to build broader and more elaborate vocabularies. Music also has the power to enhance students' range of language opportunities.

In the field of language and literacy, common discourse is moving toward multimodality (Rowsell, 2013; Winters, 2010) and the affordances of different sign systems (e.g., sonic, written or spoken text, gestures). Some have argued that music and language share similar constructions (Montgomery, 2002). However, Reimer, 2003, suggested that if music and language were, in fact the same, then "we would not need music: words or other language-symbols would serve just as well" (p. 134). For this reason, we felt it necessary to explore both vantage points alongside our vignettes.

Based upon two ethnographically-framed studies and the use of two real-life vignettes, our article hopes to have demonstrated how singing and musical experiences (whether biologically or socially shaped) may provide opportunities to celebrate language and to enhance children's lexical acquisition and semantic knowledge at various levels of development.

\section{References}

Acredolo, L., \& Goodwyn, S. (1996). Baby signs. Chicago, IL: Contemporary Books.

Barrett, M. S. (2006). Inventing songs, inventing worlds: the 'genesis' of creative thought and activity in young children's lives. International Journal of Early Years

Education, 14(3), 201-220.

Benton, M. (1992). Secondary worlds: Literature teaching and the visual arts. Philadelphia, PA: Open University Press.

Berko-Gleason, J. (2001). The development of language. New York, NY: Allyn \& Bacon. Berger, B. (1984). Grandfather twilight. New York, NY: Paperstar. 
Bernstein, L. (1976). The unanswered question: Six talks at Harvard. Cambridge, MA: Harvard University Press.

Bresler, L. (2006). Ethnography, phenomenology, and action research in music education. Visions of Research in Music Education, 8, 1-30.

Campbell, D. (2000). The Mozart effect for children. New York, NY: William Morrow.

Campbell, P. S. (2004). Teaching music globally: Experiencing music, expressing culture. New York, NY: Oxford University Press.

Campbell, P. S. (2010). Songs in their heads: Music and its meaning in children's lives (2nd ed.). New York, NY: Oxford University Press.

Campbell, P. S., \& Wiggins, T. (Eds.) (2013). The Oxford handbook of children's musical cultures. Oxford, UK: Oxford University Press.

Cohen, A. (2010). Advanced interdisciplinary research in singing: Development, education, and well-being: Milestone document (April 1, 2009-September 30, 2012). Retrieved from: http://www.airsplace.ca/node/453

Creswell, J. W. (2012). Educational research: Planning, conducting, and evaluating quantitative and qualitative research (4th ed.). Boston, MA: Pearson Education.

Emerson, R. M., Fretz, R. I., \& Shaw, L. L. (2011). Writing ethnographic fieldnotes (2nd ed.). Chicago, IL: The University of Chicago Press.

Eliot, L. (2000). What's going on in there? How the brain and mind develop in the first five years of life. New York, NY: Bantam Books.

Fedorenko, E., Patel, A., Casasanto, D., Winawer, J., \& Gibson, E. (2009). Structural integration in language and music: Evidence for a shared system. Memory \& Cognition, 37(1), 1-9.

Giles, C., Andre, M., Dye, C., \& Pfannesstiel, V. (1998). Constant connections through literature-using art, music, and drama. Language Arts, 76(13), 48-62.

Graham, B. (2000). Sounds surround us. In B. Hanley \& B. A. Roberts (Eds.), Looking forward: Challenges to Canadian music education (pp. 157-168). Victoria, BC: Canadian Music Educators' Association.

Griffin, S. M. (2007). The musical lives of children: A missing perspective in elementary school music. Unpublished doctoral dissertation, University of Alberta, Edmonton, Canada.

Griffin, S. M. (2009). Listening to children's music perspectives: In and out of school thoughts. Research Studies in Music Education, 31(2), 161-177.

Griffin, S. M. (2011). Through the eyes of children: Telling insights into music experiences. Visions of Research in Music Education, Vol 19, 1-26.

Hammersley, M., \& Atkinson, P. (2007). Ethnography: Principles in practice (3rd ed.). New York, NY: Routledge.

Harp, B. (1988). When the principal asks, "Why are your kids singing during reading time?" Reading Teacher, 1, 454-455.

Hoff, E., \& Naigles, L. (2002). How children use input to acquire a lexicon. Child Development, 73(2), 418-433.

Kit, C. (2003). How does lexical acquisition begin? A cognitive perspective. Cognitive Science, 1(1), 1-50. 
Lehrdahl, F., \& Jackendoff, R. (1983). A generative theory of tonal music. Cambridge, MA: MIT Press.

Levine, L. E., \& Munsch, J. (2010). Child development: An active learning approach. London, UK: Sage.

Lobel, A. (1980). The camel dances. Mexico: Harper-Collins.

Locke, J. (1990). Structure and stimulation in the ontogeny of spoken language.

Developmental Psychology, 23(7), 621-644.

Manolson, A. (1992). It takes two to talk. Toronto, Ontario, Canada: The Hanen Centre.

Montgomery, A. P. (2002). Teaching towards musical understanding: A handbook for the elementary grades. Toronto, ON: Pearson Education Canada.

Montgomery, A. P. (2012a). Bridging the advocacy gap with song-based picture books. Canadian Music Educator, 54(2), 41-44.

Montgomery, A. P. (2012b). 'Over in the meadow' and beyond: Singing for the joy with song-based picture books. Canadian Music Educator, 53(4), 29-32.

North, A., \& Hargreaves, D. (2008). The social and applied psychology of music. Oxford, UK: Oxford University Press.

Pan, B. A. (2001). Semantic development: Learning the meaning of words. In J. BerkoGleason (Ed.), The development of language (pp. 112-147). New York, NY: Allyn \& Bacon.

Public Broadcasting System. (1985). Baby talk [television broadcast].

Peretz, I. (2006). The nature of music from a biological perspective. Cognition, 100(1), $1-32$.

Piro, J. M., \& Ortiz, C. (2009). The effect of piano lessons on the vocabulary and verbal sequencing skills of primary grade students. Psychology of Music, 37(3), 325-347.

Reimer, B. (2003). A philosophy of music education: Advancing the vision (3rd ed.). Upper Saddle River, NJ: Prentice Hall.

Rosenblatt, L. (1978). The reader, the text, the poem; The transactional theory of the literary work. Carbondale: Southern Illinois University Press.

Rowsell, J. (2013). Working with multimodality: Rethinking literacy in a digital age. London, UK: Routledge.

Smithrim, K., \& Upitis, R. (2007). (Eds.), Listen to their voices: Research and practice in early childhood music. Waterloo, ON: Canadian Music Educators' Association.

Stone, C. A., Silliman, E. R., Ehren, B. J., \& Apel, K. (2004). Handbook of language \& literacy: Development and disorders. New York, NY: The Guilford Press.

Streeter, L. (1976). Language perception of two-month-old infants shows effects of both innate mechanisms and experience. Nature, 259(5538), 39-41.

Tomasello, M. (2003). Constructing a language: A usage based theory of language acquisition. Cambridge, MA: Harvard University Press.

Van Maanen, J. (2011). Tales of the field: On writing ethnography ( $2^{\text {nd }}$ ed.). Chicago, IL: The University of Chicago Press.

Winters, K-L. (2010). Quilts of authorship: A literature review of multimodal assemblage in the field of literacy education. Canadian Journal for New Scholars in Education, 3(1). http://www.cjnse-rcjce.ca/ojs2/index.php/cjnse/article/viewArticle/161 
Winters, K-L. (2013). Beyond words. Using the arts to enhance early reading comprehension. Birmingham, AL: Look Again Press.

\section{Author Biographies}

Dr. Kari-Lynn Winters, Associate Professor in Literacy and Drama Education, Brock University, obtained her $\mathrm{PhD}$ and MEd from the University of British Columbia, BEd from OISE/UT, and Honours BA from Brock University. Kari-Lynn is an award-winning educator, Canadian children's author, and playwright. Her research interests include: teacher education, multimodal authorship, arts integration, literacy, and children's literature. Kari-Lynn's work is widely known, both nationally and internationally.

Dr. Shelley M. Griffin, Associate Professor of Elementary Music Education, Brock University, obtained her PhD and MEd from the University of Alberta and her Bachelor of Music from the University of Prince Edward Island. Her research interests include: children's narratives of musical experiences, pre-service music teacher education, narrative inquiry, informal faculty mentorship, and collaborative scholarship. Shelley has published in several music education journals and has contributed chapters to books on narrative inquiry. 